\title{
Effect of Globalisation on Food Behaviour Among Badagas
}

\author{
Sonali. R, R. Ramaprabha \\ PSG College of Arts and Science, Coimbatore, India
}

\begin{abstract}
An ethnography study was conducted among five villages in Kotagiri district of Tamil Nadu, to identify "how globalisation affects the food behaviour of Badagas". The research is a qualitative study, having implemented Vygotsky's socio-cultural theory. The traditional food processed and prepared by women of Badagar community is intimately connected to their socio-cultural, ecological, and spiritual life and health. The processing and preparation of ethnic foods demonstrate not only the creativity and treasure of food heritage of tribal women, but also their incremental learning to sustain the life and ecosystem as a whole. Looking to the diversities in ethnic foods, an attempt has been made to explore the ethnic foods from five different villages in Kotagiri district. The food choices made by people, either as individuals or as a group, can reveal views, passions, background knowledge, assumptions, and personalities. Food choices tell stories of families, migrations, assimilation, resistance, changes over times, and personal as well as group identity. In each place, the processing method of these foods is somewhat different based on the growing international trade, migration, tourism, and globalisation. The food used in the dietary system was found to be nutritionally rich and culturally important in various festivals and ceremonies. Ethnic food prepared and consumed by women in the past cannot be seen in the isolated mode, instead it is a complex dynamics in which nutrition, health, food security, culture, ethics, subsistence economy, and ecological sustainability are integral components. This paper thereby determines and defines the behaviour and practice of food among the respondents, its change, and cause.
\end{abstract}

Keywords: Ethnography, Kotagiri District, Vygotsky's Socio-cultural Theory, Ethnic food Behaviour, Effect of Globalisation

\section{Introduction}

People connect to their cultural or ethnic group through similar food patterns. Immigrants often use food as a means of retaining their cultural identity. People from different cultural backgrounds eat different foods. The ingredients, methods of preparation, preservation techniques, and types of food eaten at different meals vary among cultures. Regional food habits do exist, but they also change over time. As people immigrate, food practices and preferences are imported and exported. Families move to other locations, bringing their food preferences with them. They may use their old recipes with new ingredients, or experiment with new recipes, incorporating ingredients to match their own tastes.

${ }^{1}$ The Nilgiris district population is about seven lakh when the population of the Badagas is around 2.5 lakh. An increasing number is migrating from their community in the Nilgiris to the city.

Sonali. R, M. Phil., Scholars, Department of Communication, PSG College of Arts and Science.

R. Ramaprabha, Ph.D., Assistant Professor, Department of Communication, PSG College of Arts and Science.

${ }^{1} \mathrm{https} / / /$ timesofindia.indiatimes.com/city/coimbatore/Badagas-to-dig-into-their-past/articleshow/13159221.cms. 
Badagas are inspirational and zealous people who have made their home amidst the Ooty hills. The main occupation of the people in this community is agriculture. Tea plantation is the major agriculture here. The Badaga tradition and culture is very unique. They enjoy full cultural freedom excitement in terms of the various festivities, dance, and music. As in any culture, food is an integral part of Badaga culture. There are occasion-based foods, daily foods, and seasonal foods. Badagas being nature lovers, most of their customs are nature-oriented, which means they live healthy. Food especially is prepared with a lot of ardour and care. The study is going to be about how globalisation affects the food culture of Badagar community.

The traditional foods processed and prepared by women of Badagar community are intimately connected to their socio-cultural, ecological, and spiritual life and health. The processing and preparation of ethnic foods demonstrate not only the creativity and treasure of food heritage of the respondents, but also their incremental learning to sustain the life and ecosystem as a whole.

The ancestors consumed what they grew and made sure they replenished the soil and prepared almost everything from scratch. If they wanted butter, they would churn milk using a pot and plunger, a rope, and bare hands. This process called haalu sorakodu has now been replaced by mixers and machines. Even the hati maasu hudi (masala used in the gravies) was homemade but is now available readymade in shops. Since everything was hand milled, there was no adulteration and the food was extremely healthy. People stayed active and there was plenty of social interaction when relatives or neighbours lent a helping hand in grinding and pounding.

\section{Review of Literature}

\section{Ethnic Food Attitudes and Behaviour Among Belgians and Hispanics Living in Belgium}

Awareness and testing of ethnic cuisine have increased in the past decades as a consequence of the growing international trade, migration, tourism, and globalisation. This article aims to focus on the attitude and behaviour of Belgians towards Latin-American ethnic foods and of Hispanics living in Belgium towards mainstream Belgian food. The overall opinion and degree of satisfaction of the Belgian sample towards ethnic food were favourable. Latin-American food consumption and attitude of Belgians are negatively correlated with food neophobia, which is significantly higher among urban and 55+ aged consumers, and positively correlated with openness to new cultures. Taste and appearance were key attributes that determined Belgians' preference for ethnic foods. Hispanics' general perception towards Belgian mainstream food was favourable as well, although they considered their own food as being better in taste. Barriers to maintain Latin-American food habits are availability and time constraints. Hispanics' adoption of traditional Belgian cuisine is positively correlated with time of residence in Belgium and negatively correlated with maintenance of native social interaction and language use. Food neophobia does not emerge as a determinant of Hispanics' dietary acculturation to mainstream Belgian food (Verbeke \& Poquiviqui López, 2005).

\section{Food and Identity: Food Studies, Cultural, and Personal Identity}

This study was inspired by the author's academic travel to Naples, Italy to study the food habits of those who live in that region and follow the Mediterranean diet. The author introduces the concept of food studies and explores the relationship of food to the human experience. Food studies challenge researchers to delve into the common daily occurrence of eating and find deeper meaning in this everyday practice. By examining what, where, how, and why of our food choices and food habits, we develop a better understanding of ourselves and others. Applying a food studies mind set allows researchers across disciplines to debunk food related 
stereotypes and promotes acceptance across individuals and groups. The author also explores the relationship of this field of study to standards espoused by the National Council of the Social Studies to determine where and how food studies fit into the school curriculum (Almerico, 2014).

\section{Exploring Food Neophobia and Perceptions of Ethnic Foods: The Case of Chinese and Thai Cuisines}

This preliminary study explored the application of Pliner and Hobden's (1992) food neophobia scale (FNS), and the food attitudes scale (FAS) established by Aikman, Crites, and Fabrigar (2006) for measuring perceptions of ethnic cuisines among the college-age population of the upper Midwest. Although the FNS was stable and factored as expected, the FAS was not suitable for evaluating cuisines as a whole instead of specific food items. Additionally, individuals who were highly food neophobic exhibited greater negative attitudes towards Chinese and Thai cuisines. Conversely, individuals who were low on the food neophobic continuum exhibited more positive attitudes towards the cuisines (Asperin, Phillips, \& Wolfe, 2011).

\section{Cultural Significance and Diversities of Ethnic Foods of Northeast India}

The traditional foods processed and prepared by women of Northeastern region are intimately connected to their socio-cultural, ecological, and spiritual life and health. The processing and preparation of ethnic foods demonstrate not only the creativity and treasure of food heritage of tribal women, but also their incremental learning to sustain the life and ecosystem as a whole. Looking to the diversities in ethnic foods, an attempt has been made to explore the ethnic foods made of local soybean, bamboo shoot, tree bean, lai patta (leafy mustard) and rai (Brassica juncea (Linn.) Czern. \& Coss.) from different selected tribes of Northeast India (A. Singh \& R. K. Singh, 2007).

Tribal women of Northeastern region have a wide range of variability in the ethnic foods made of soybean, bamboo shoot, lai patta, tree bean, and rai. In each state, the processing method of these foods is somewhat different based on the culture, variability in the materials used in the food, climate, and overall knowledge of the processing and preparation. The foods used in the dietary system were found to be nutritionally rich and culturally important in various festivals and ceremonies. Ethnic foods prepared and consumed by women cannot be seen in the isolated mode, instead it is a complex dynamics in which nutrition, health, food security, culture, ethics, subsistence economy, and ecological sustainability are integral components. A policy framework with clear directives on recognition of traditional foods and associated knowledge systems is urgently needed.

\section{Research Methodology}

\section{Need for the Study}

Food study is not the study of food itself; it is an emerging interdisciplinary field of study that observes the intricate relationships among food, culture, and society. The study is to identify how the food behaviour of the Badagar community people has changed in the past decades as a consequence of the growing international trade, migration, tourism, and globalisation. The study focuses on identifying the barriers among Badagas to maintain their ethnic food habits.

\section{Objective}

To find how globalisation affects the food habits of Badagas.

\section{Research Question}

How does globalisation affect the food habits of Badagas? 


\section{Method}

The study employs qualitative method using unstructured questionnaire and face-to-face interview to gather information from the Badagas on their food habits. It is a longitudinal study as the sample grouping of age is categorised as per decades.

\section{Sampling}

Convenience sampling method.

\section{Sample Size}

Fifty from five different villages around Kotagiri.

\section{Age Categories}
(1) $90-80$;
(2) $80-70$;
(3) $70-60$;
(4) 60-50;
(5) $50-40$.

\section{Occupation}

(1) Working;

(2) House wife.

\section{Education}

(1) Primary;

(2) Higher secondary;

(3) Graduate;

(4) Post graduate.

\section{Theoretical Frame Work}

The study was formulated by implementing Vygotsky's socio-cultural theory to theoretically analyze the findings.

\section{Material and Methods}

A survey was carried out to study how globalisation affects food habits of Badagar community with the age group between 40-90 years old. An open-ended questionnaire was designed and the women with the age up to 40 were interviewed personally and their details were collected.

\section{Place of Survey}

Personal report of 50 women was collected from five villages-Nedugula Hosatty, Battagorai, Kaavilorai, Jakambai, and Beragani (Hettai Mana Keri) belonging to Badagar community.

\section{Theoritical Framework-Socio-cultural Theory-Lev Vygotsky}

Socio-cultural theory grew from the work of seminal psychologist Lev Vygotsky, who believed that parents, caregivers, peers, and the culture at large were responsible for developing higher order functions (Vygotsky, 1978; 1986; 1987).

According to Vygotsky, learning has its basis in interacting with other people. Once this has occurred, the information is then integrated on the individual level: 
Every function in the child's cultural development appears twice: first, on the social level, and later, on the individual level; first, between people (inter psychological) and then inside the child (intra psychological). This applies equally to voluntary attention, to logical memory, and to the formation of concepts. All the higher functions originate as actual relationships between individuals. (Vygotsky, 1978)

\section{Findings}

The Badagas are portrayed in literature as a caste in South India with a population of 160,000 . An increasing number is migrating from their community from the Nilgiris to various cities.

Data are collected from a relatively small convenience sample, which limits generalisation of the findings beyond the sample characteristics, which renders the findings exploratory rather than conclusive. This paper covers important research subjects, namely attitude, perceptions, and behaviour towards ethnic food and food consumption among Badagas in the increasingly globalised food market.

\section{Age :}

\section{0 responses}

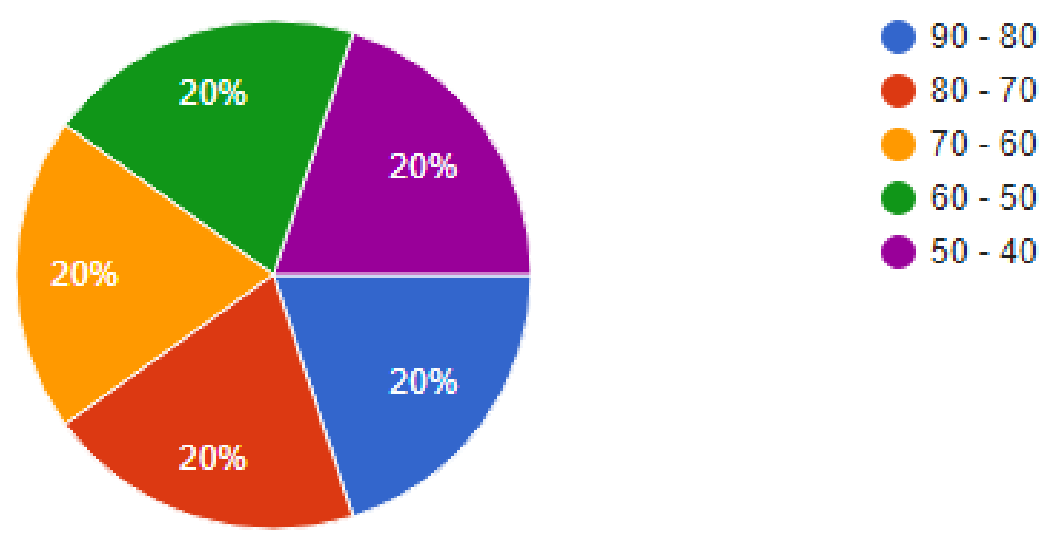

Figure 1. Age of the respondents.

The five age groups comprise of $20 \%$ of the respondents who participated in the survey (see Figure 1). Therefore, the sample is equally distributed among the five age groups. This has been done purposively to analyze the change that occurs in food consumption over each decade.

\section{Place of Survey}

Personal report from 50 women was collected from five villages-Nedugula Hosatty, Battagorai, Kaavilorai, Jakambai, and Beragani (Hettai Mana Keri) belonging to Badagar community.

Majority of the respondents (30\%) have been educated up to higher secondary, $24 \%$ of the respondents are primary and secondary educated, $12 \%$ of the respondents are under graduate, and a minority of $10 \%$ of the respondents are post graduate (see Figure 2). 


\section{Educational Qualification}

\section{0 responses}

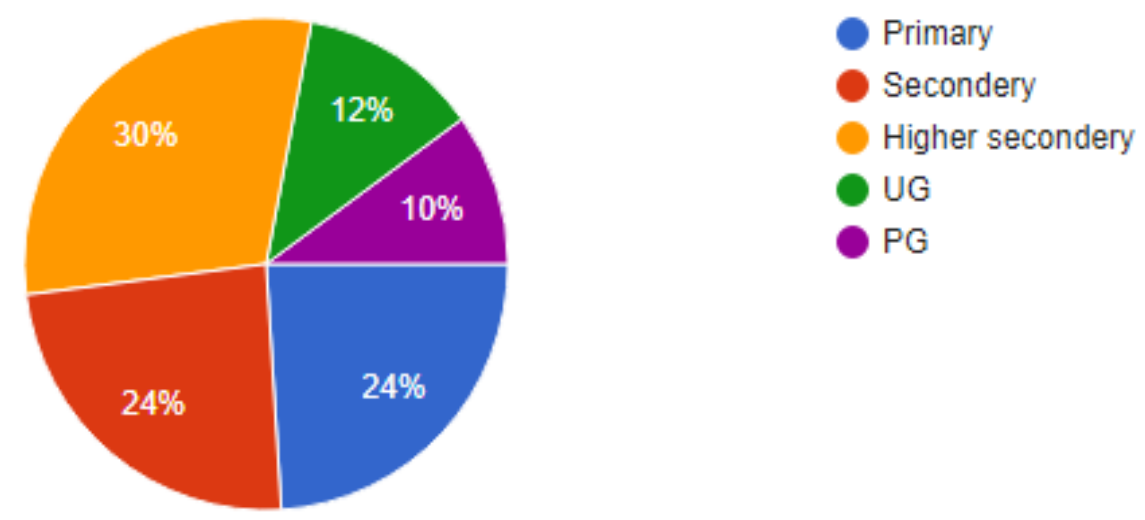

Figure 2. Education qualification of the respondents.

\section{Occupation of the Respondents}

Seventy-four percent of the respondents are home makers and $26 \%$ of the respondents are working.

\section{Staple Food of Badagas}

Staple food of Badagar community are beans, bellaku, aaluku, bennaku, ubittu, ottukudi (bamboo shoots), kajai, iri dhoti, badagaru koi udakka (badaga chicken curry), koi udaka maasu hudi (masala powder for chicken gravy), udaka maasu hudi (for other gravies), thuppadhittu (enne hittu) "a sweet dish", belle benguvae sandege (garlic side dish), eera benguvae sandege (onion side dish), belle benguve maasu neer, Badaga chicken special, kadamittu, hattchike, bellaganji.

\section{Badaga Produce}

Badagas usually grow vegetables and fruits in their small patches of land called "HOLA" for their regular use apart from other commercial crops like potato, cabbage, carrot, cauliflower, etc. These would also include many varieties of beans, peas, greens, corn, etc. Every variety of avarai (bean) has a specific (sometimes unique) Badaga name.

\section{Native Fruits of Badagas}

The native fruits of Badagas are tree tomato, biky, passion fruit, panner fruit, custard apple, plums, thavittu palam, pear, and peach.

\section{Native Vegetables of Badagas}

The native veggies of Badagas are turnips, beans, cabbage, potato, beetroot, green leaves, raddish, corn, cauliflower, onion, and garlic. 


\section{Food Consumption Pattern}

When it comes to consumption of traditional food, food making pattern is of great importance. It is unfortunate that there is a drastic change in the pattern of making food at the present juncture. Badaga people still consume traditional food but the food making and food intake pattern differ, which is the reason why it is marked "nil" in the below table (see Table 1).

Table 1

Consumption of Ethnic Food Among the Respondents

\begin{tabular}{lll}
\hline Food pattern & $\begin{array}{l}\text { Consumption of ethnic food among } \\
\text { the respondents in the past (\%) }\end{array}$ & $\begin{array}{l}\text { Consumption of ethnic food among } \\
\text { the respondents in the present (\%) }\end{array}$ \\
\hline Breakfast & $78 \%$ & $38 \%$ \\
$\begin{array}{l}\text { Eragi hittu } \\
\text { Pothittu }\end{array}$ & $12 \%$ & Nil \\
Rice & $10 \%$ & Nil \\
Lunch & & \\
Pothittu with tea & $54 \%$ & Nil \\
Meals & $46 \%$ & Nil \\
Snack & & \\
Variki, salt biscuits, roasted rice called gangikai & $100 \%$ & Nil \\
are some of the crispy snacks with tea & & \\
Dinner & $90 \%$ & Nil \\
Rice & $10 \%$ & Nil \\
Pothittu & & \\
\hline
\end{tabular}

\section{The Past Food Behaviour of the Respondents}

The ancestors consumed what they grew and made sure they replenished the soil and prepared almost everything from scratch. Majority of the Badagar community belong to the agriculture sector.

Having to undergo heavy field work, their breakfast consumed is rather excess when compared to lunch and dinner. Their breakfast behaviour is as follows:

(1) $78 \%$ of the respondents consumed eragi hittu, which is made of finger millets and is a healthy alternative to rice and wheat. A depression is made in the mudde and ghee poured into it. It is then eaten with soppu (greens) and avarai udaka (beans curry);

(2) $12 \%$ of the respondents consumed pothittu (wheat dosa);

(3) $10 \%$ of the respondents consumed rice.

Consumption of food is less when compared to breakfast, the reason being, heavy lunch may ruin better workmanship.

(1) $54 \%$ of the respondents consumed pothittu with tea;

(2) $46 \%$ of the respondents consumed meals.

Variki and salt biscuits, roasted rice called as gangikai are some of the crispy snacks with tea (100\%).

The fried ganje called ganjikke would be taken with bella (jaggery) and thenke (coconut). The taste of this would increase if hurutha keerai is added.

This gangikai would be powdered in a beesa gallu or beesaran kallu (grinding stone "flour mill") that was a permanent feature in the edha or nadu mane (living room) and stored for future use. People who go on long journeys (in olden days travel was by foot only) took this powder along with them, a very handy and healthy 
meal. This powder would be mixed with hot water to make gruel. Salt and jaggery could be added to taste.

Having returned exhausted from field work and breakfast being the only source of main course of food:

(1) $90 \%$ of the respondents generally consumed rice for dinner;

(2) $10 \%$ of the respondents consumed pothittu.

\section{Present Food Behaviour of the Respondents}

The existence of the past food behaviour of the Badagar community still prevails but is being dominated by the present food behaviour.

(1) $38 \%$ of the respondents still consume eragi hittu;

(2) $32 \%$ of the respondents consume idly, dosa, puri, etc.;

(3) $18 \%$ of the respondents consume both the past and present food depending on their appetite;

(4) $12 \%$ of the respondents consume porridge due to health issues.

Majority of $60 \%$ of the respondents consume both meals and variety rice for lunch, $34 \%$ of the respondents consume only meals and $6 \%$ of the respondents still consume pothittu.

The homemade edibles of the past for snacks had been replaced by the easily available readymade products.

(1) A maximum of $32 \%$ of the respondents do not consume any kind of snack for various reasons;

(2) $28 \%$ of the respondents consume the snack based on its availability at home;

(3) $22 \%$ of the respondents prefer hot cooked snack like bajji, vadai, etc.;

(4) $18 \%$ of the respondents consume bakery items, such as biscuits, chips, cakes, etc.

A total of $38 \%$ of the respondents consume chapathi, $32 \%$ of the respondents consume dosa, idly, puri, etc., $16 \%$ of the respondents consume all kinds of food, and $14 \%$ of the respondents consume rice for dinner.

\section{Food Tradition During Special Occasions}

Badaga occasion is incomplete without "Avare \& Gaasu udakka" (beans \& potato curry). The food tradition during special occasions is still being followed the same because of the older generation, whereas the younger generation is less aware of the traditional food making and food intake pattern.

During pregnancy, women consume bellaku, panabella, jeera kashayam, coriander kashyam, aaluku, and kappu udhaka. In the present as people move to cities and live apart from their family, they very rarely practice the traditional food behaviour.

During festivals, the main dishes prepared and consumed are kajai, thuppadhittu, ubbitu, diamond cut, and kallimittu. The younger generation is less aware of the traditional food making and food intake pattern. Hence it is in the verge of fading.

Incidentally, Badagas do not serve non-vegetarian (meat) dishes on the wedding day, and main meal is called "maduve hittu".

During funerals, avarai udaaka and rice along with ghee are served at the death of elderly persons whereas dhal and rice are served for those who pass away as in early age.

There are plenty of reasons for the change in food behaviour among the respondents. Forty percent of the respondents reasoned globalisation, $20 \%$ of the respondents reasoned ease and health issue, $14 \%$ of the respondents reasoned nuclear family, and $6 \%$ of the respondents reasoned immigration. 


\section{Why this Change?}

50 responses
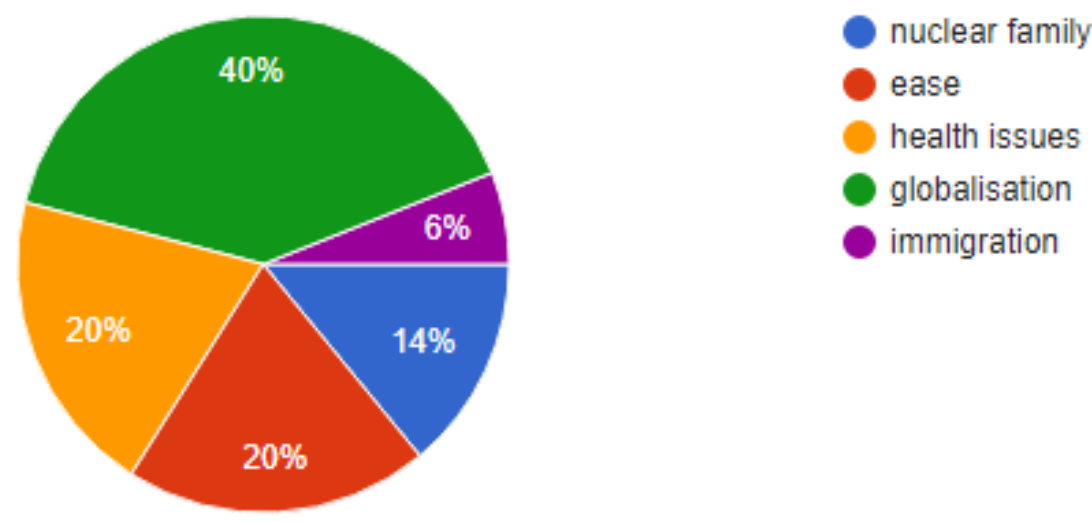

Figure 3. Reason for change in food behaviour.

\section{Implementation of Theory}

A study on effect of globalisation on Badagar food behaviour posits the change in food behaviour from the past to present. Food behaviour being a serious social issue and food practice having been a cultural issue have a inter dependence leading to the socio-cultural aspect. Therefore, Vygotsky's socio-cultural theory has been implemented in this study to reveal the elements of socio-culture pertaining to the effect of globalisation on the behaviour and practice of food among the respondents.

According to Vygotsky, children are born with basic biological constraints in their minds. Each culture, however, provides what he referred to as "tools of intellectual adaptation". These tools allow children to use their basic mental abilities in a way that is adaptive to the culture in which they live.

From the study, it has been found that, the women of the Badagar community are urged to have a hold on change. The study has adapted Vygotsky's socio-cultural theory, which explicates inter psychological and intra psychological aspects which play a vital role in analyzing the change in food behaviour among the respondents.

\section{Interpretation and Discussion}

A survey was carried out to study how globalisation affected the food habits of the Badagar community. An open-ended questionnaire was designed for the women of the age group between 40-90 who were interviewed personally and their details on food behaviour were collected. Despite having the past day food at present, it is unfortunate that there is a drastic change in the pattern of making food at the present juncture. When it comes to consumption of traditional food, food making pattern is of great importance. Badaga people still consume traditional food but the food making and food intake pattern differ. Hence, there is a change in the food behaviour.

Taste and appearance are the key attributes that determine Badagas preference for ethnic foods in the present. In the present, Badagas general perception towards other food is approving, although they consider 
their own food as being better in taste. Barriers to maintain their ethnic food habits are availability and time constraints. Food neophobia does not emerge as a determinant of Badagas dietary acculturation.

The research of the Badagar food behaviour put forth several reasons that mark their change in the practice of food over decades.

(1) Regional food habits do exist, but they changed over time;

(2) Immigration plays a strong role for the change of food behaviour. As people immigrate, food practices and preferences are imported and exported;

(3) The emergence of hotels and restaurants in the recent past provoked the respondents to try new dishes that over lapped the past behaviour;

(4) Consumption of time is another important reason for change in food behaviour. Depending on the availability and certainty of food, the respondents prefer the present day food behaviour as it is prepared at ease;

(5) Nuclear families also contributed to the change in food behaviour for the above reason;

(6) In the past, consumption swung between plenty and want dependant on harvest and seasons;

(7) In the present, choice was limited and dependent on availability and status. This paved way to nutritional inequalities within the society, in the present, having resulted in various health issues which were absent in the past;

(8) Since change is inevitable, the present day food behaviour tends to dominate the practice of the past due to globalisation.

\section{Conclusion}

The study, "Effect of Globalisation on Food Behaviour Among Badagas", lays forth the change in food practice. It was found that the respondents favour the past food habits when compared to that of the present. However, having imbibed the changes of the present, the respondents adapt themselves to today's generation. Nevertheless, practices of past traditions do have their existence in the present, engulfing the new practice. The study states the change in food behaviour and practice among the respondents underwent several changes over decades for reasons, such as immigration, growing international trade, tourism, and globalisation.

There is a change in the staple food of Badagar community because the food making and food intake pattern differ in the present juncture.

The great trade and custom of Badagar community is food sharing. The agricultural produce, food, and dishes are being shared among relatives, friends, and guests.

The production of food in the past was small scale/limited and locally based for all whereas in the present, the production of food is in large scale, highly specialized, industrialized, de-localised, and globalised. Earlier, consumption was dependent on harvest and season, wherein today food is always available at a price, independent of season. Barriers to maintain the ethnic food habits are availability and time constraints.

\section{References}

Aikman, S. N., Crites, L. J., \& Fabrigar, L. R. (2006). Beyond affect cognition: Identification of the informational bases of food attitudes. Journal of Applied Social Psychology, 36(2), 340-382.

Almerico, G. M. (2014). Food and identity: Food studies, cultural, and personal identity. Journal of International Business and Cultural Studies, 8, 1-7. 
Asperin, A. E., Phillips, W. J., \& Wolfe, K. (2011). Exploring food neophobia and perceptions of ethnic foods: The case of Chinese and Thai cuisines. Retrieved from http://docplayer.net/75665500-Exploring-food-neophobia-and-perceptions-of-ethnic-foods-the-case-of-chinese-and-thai-cuisi nes.html

Beardsworth, A., \& Keil, T. (2002). Sociology on the menu: An invitation to the study of food and society. New York, NY: Routledge.

Counihan, C., \& Van Esterik, P. (2012). Food and culture: A reader. New York and London: Routledge.

Cook, J. T., Frank, D. A., Berkowitz, C., Black, M. M., Casey, P. H., Cutts, D. B., ... Heeren, T. (2004). Food insecurity is associated with adverse health outcomes among human infants and toddlers. The Journal of Nutrition, 134(6), 1432-1438.

Harris, M. (1998). Good to eat: Riddles of food and culture. Long Grove, IL: Waveland Press.

Pliner, P., \& Hobden, K. (1992). Development of a scale to measure the trait food neophobia in humans. Appetite, 19, 105-120.

Singh, A., \& Singh, R. K. (2007). Cultural significance and diversities of ethnic foods of Northeast India. Indian Journal of Traditional Knowledge, 6(1), 79-94.

Verbeke, W., \& Poquiviqui López, G. (2005). Ethnic food attitudes and behaviour among Belgians and Hispanics living in Belgium. British Food Journal, 107(11), 823-840.

Vygotsky, L. S. (1978). Mind in society: The development of higher psychological processes. Cambridge, MA: Harvard University Press.

Vygotsky, L. S. (1986). Thought and language. Cambridge, MA: MIT Press. (Original work published in 1934)

Vygotsky, L. S. (1987). Thinking and speech. (N. Minick, Trans.). New York: Plenum Press. 